\title{
What Caused the Drop in European Electricity Prices? A Factor Decomposition Analysis
}

\author{
Lion Hirth*
}

\begin{abstract}
European wholesale electricity prices have dropped by nearly two thirds since their all-time high around 2008. Different factors have been blamed, or praised, for having caused the price slump: the expansion of renewable energy; the near-collapse of the European emissions trading scheme; over-optimistic power plant investments; a decline in final electricity consumption; and cheap coal and natural gas. This ex-post study of European electricity markets from 2008 to 2015 uses a fundamental power market model to quantify their individual contributions on day-ahead prices. The two countries we study in detail, Germany and Sweden, differ significantly: fuel and $\mathrm{CO}_{2}$ prices were important price drivers in Germany, but in Sweden it was electricity demand. This difference is explained by the nature of the hydro-dominate Nordic electricity system. In both countries, however, the single largest factor depressing prices was the expansion of renewable energy. At the same time, Germany's nuclear phase-out had an upward effect on prices. If one defines the Energiewende as the combination of these two policies, its net effect on power prices was negligible.
\end{abstract}

Keywords: electricity price; ex-post analysis; utility crisis.

https://doi.org/10.5547/01956574.39.1.1hir

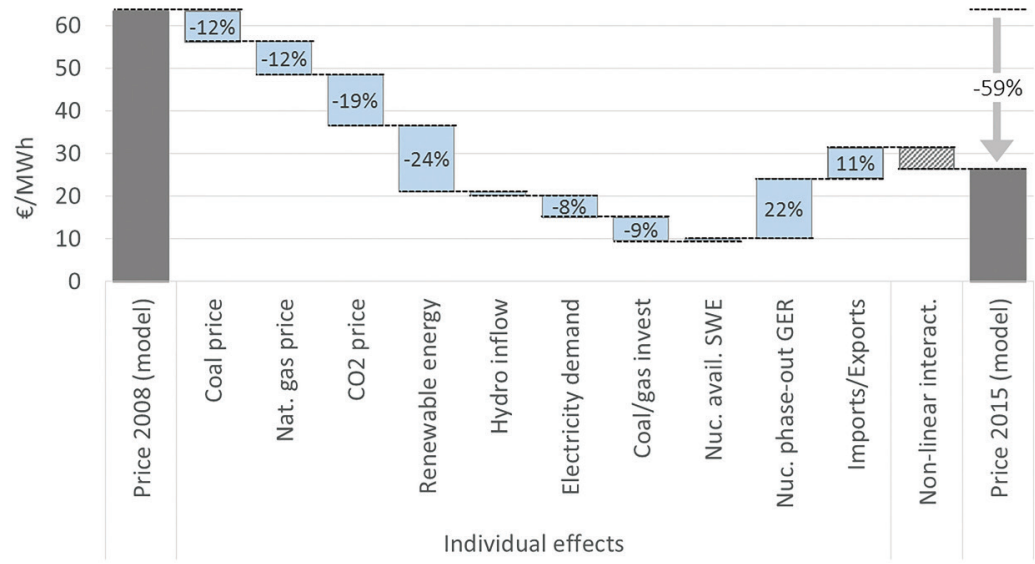

Graphical abstract-The change in German spot prices from 2008 to 2015, showing the contribution of ten individual drivers. Numbers indicate the price impact of an individual factor relative to 2008 prices. For example, the decline of coal prices on its own would have caused an electricity price drop of $12 \%$. In contrast, the nuclear phase-out alone would have increased prices by $22 \%$ from 2008 levels. Overall, electricity prices fell by $59 \%$.

* Neon Neue Energieökonomik GmbH, Karl-Marx-Platz 12, 12043 Berlin, Germany; hirth@neon-energie.de; +49 1575 5199715, www.neon-energie.de. Hertie School of Governance; and Mercator Research Institute on Global Commons and Climate Change (MCC), Germany.

The Energy Journal, Vol. 39, No. 1. This is an open access article under the terms of the Creative Commons Attribution License (CC-BY), which permits use, distribution and reproduction in any medium, provided the original work is properly cited. 


\section{INTRODUCTION: THE DRAMATIC DROP IN EUROPEAN POWER PRICES}

Wholesale prices for electricity in Europe have witnessed a dramatic decline during recent years. For example, prices in both Germany and Sweden have fallen by nearly two thirds since their peak in 2008-10 (Figure 1, Figure 2).

A number of factors have been blamed - or praised - for the price slump: the expansion of renewable energy, the collapse of the European emissions trading scheme (EU ETS) allowance price, over-optimistic power plant investments, a decline in final electricity consumption, the decline in fuel prices, and abundant water inflow into hydro reservoirs. Low power plant availability and the German nuclear phase-out, in turn, have helped stabilizing the price. Figure 3 illustrates how different shocks influence electricity prices, using a "merit-order" or "supply stack" model.

Some of these changes themselves can be explained with more fundamental, "deeper-level" changes. The EU ETS price collapse, for example, has been traced back to policy interven-

Figure 2: Monthly Average Spot Prices

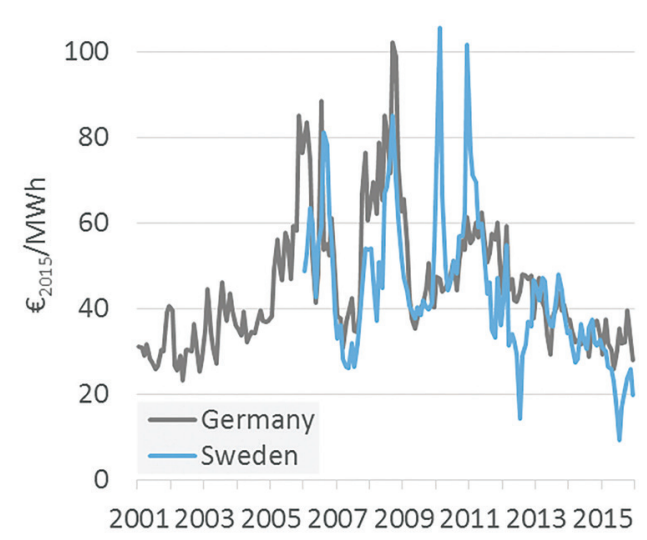

Inflation-adjusted average day-ahead spot prices in Germany and Sweden. Data source: EPEX and Nordpool
Figure 1: Annual Average Spot Prices

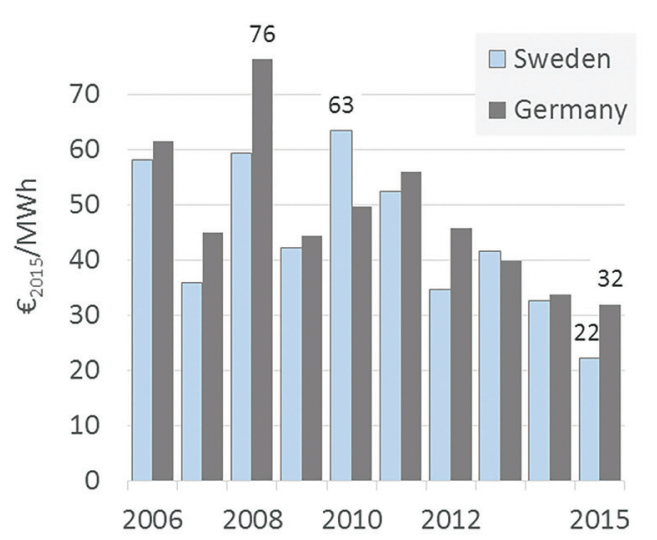

Inflation-adjusted average day-ahead spot prices in Germany and Sweden. Data source: EPEX and Nordpool

Figure 3: The Impact of Price and Quantity Shocks in a Merit-order Model of Electricity Markets

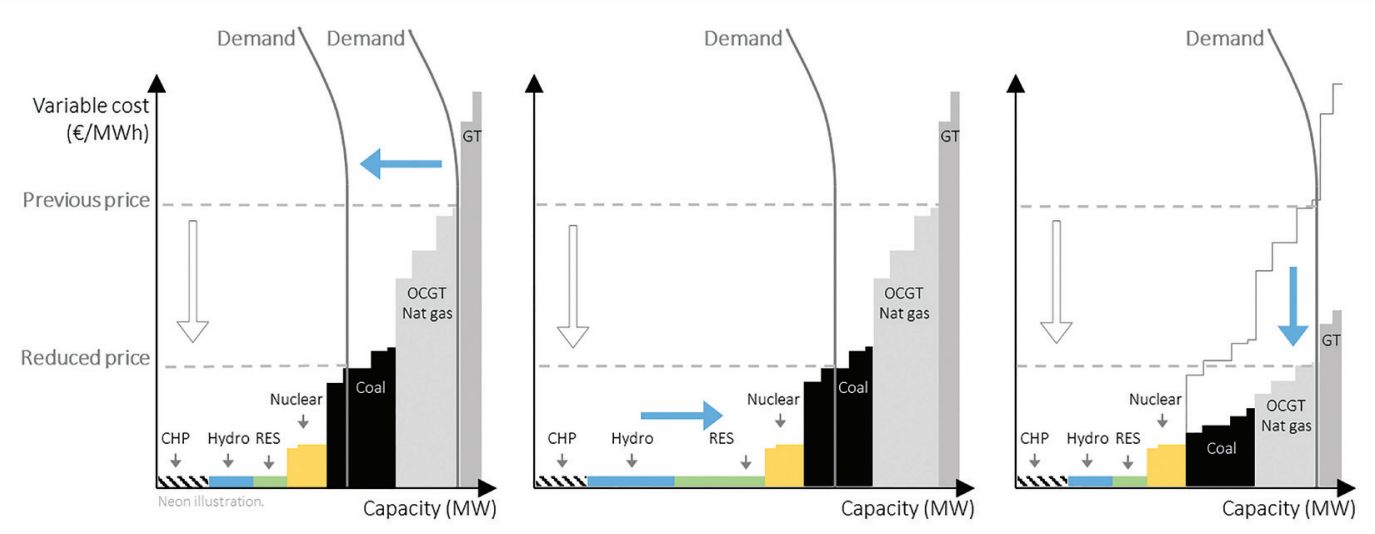

The impact of reduced electricity demand (left) is to shift the demand curve inwards. The impact of increased low-variablecost supply (middle) is to shift the supply curve outward. The impact of reduced variable cost (right) is to shift the supply curve downward. Each shock (blue arrow) leads to a price decline (white arrow). 
tions, lack of credibility, and the macroeconomic recession. Similarly, the reduction of electricity consumption has been attributed to energy efficiency policy, the macroeconomic recession, carbon leakage, and structural change in the European industry.

This paper is an ex-post study of European day-ahead spot prices from 2008 to 2015. The fundamental electricity market model EMMA is used to quantify the individual impact of above mentioned factors one by one. Initially we use the model to replicate historical prices, using input parameters from the respective year. Then individual input parameters are substituted with their 2015 value. The change in modeled electricity prices is interpreted as the ceteris paribus impact of this parameter.

A large branch of the energy economics literature discusses the price-depressing effects of increasing penetration of renewable energy - the so-called "merit-order effect" (Olsina et al. 2007, Rathmann 2007, Sáenz de Miera et al. 2008, Munksgaard \& Morthorst 2008, MacCormack et al. 2010, Mount et al. 2010, O’Mahoney \& Denny 2011, Gil et al. 2012, among others). However, while these studies estimate the price impact of one important parameter, they do not attempt to quantify all the other variables that determine electricity prices. The same is true for another branch of the literature, one that focusses on the impact of carbon pricing on the electricity price. The "passthrough" literature estimates how much of $\mathrm{CO}_{2}$ price shock generators pass on to electricity prices (Sijm et al. 2006 is an early example).

Recently, two papers have been published that investigate the reasons for the erosion of German power prices. Kallabis et al. (2016) study the plunge in electricity futures with delivery in 2014, as traded between 2008 and 2013; they investigate the change in the expectations of the market actors. Kallabis et al. find that the - unexpected - drop in $\mathrm{CO}_{2}$ certificates can explain nearly half of the price decline. In contrast, the aim of our study is to assess the change in market fundamentals, as opposed to expectations. Hence, we study spot, rather than financial, markets (see section 2.2 for further elaboration).

Another paper by Everts et al. (2016) studies German spot markets. Our paper differs from Everts et al. by adopting a broader geographic coverage - modeling the whole of Northwest Europe - and addressing a richer set of factors. Another contribution of the present paper is that it explicitly addresses a number of methodological challenges of the factor decomposition implicitly employed in all three papers (including this).

A third paper, Bublitz et al. (submitted), has been provided by the authors prior to publication. While Kallabis et al. (2016), Everts et al. (2016) and this study all apply fundamental modeling, Bublitz et al. follow a different approach. More precisely, they use two different methods to explain the price decline on German spot markets between 2011 and 2015: an agent-based model and a linear regression. Given the low level of market power, we deem agent-based modeling not necessary. The econometric approaches employed assume linear, independent relationships between exogenous variables end the electricity prices. The non-linear shape of the supply curve (recall Figure 3), and the fact that the power plant fleet changes over time give rise to doubts about the validity of this assumption. Nevertheless, the regression model yields comparable results to this study, attributing the largest effect to the expansion of renewable energy and the second-largest effect to the decline of carbon prices (Figure A.3 in Bublitz et al.).

Understanding what caused the price slump is important for a number of reasons. Obviously, understanding past price patterns helps anticipating future price developments, which is of interest for producers, consumers and traders alike. However, understanding the recent history of European power prices is also important for public policy. A number of policy interventions have affected prices $-\mathrm{CO}_{2}$ trading, subsidies for renewable energy, and Germany's nuclear phase-out, 
to name some prominent examples. These policies affect electricity prices and hence redistribute economic rents between producers and consumers and across different kinds of producers (Hirth \& Ueckerdt 2013). Sometimes redistribution might be intended, while in other cases it might be a side-effect of pursuing other policy objectives. In both cases, understanding the price impacts of past policy action can help designing future policies.

In this study, ten factors are explicitly modeled. Six of them are found to have contributed to the price decline while three have mitigated it; one is ambiguous in the direction of its effect. Detailed results are reported for Sweden and Germany. These countries have been selected because they represent two quite distinct types of markets: Germany has a predominantly fossil generation mix, while Sweden generates electricity mostly from hydropower and nuclear power. As a consequence, shocks had a different impact in each country. In Germany, the largest contributors to the decline of the power price since its peak have been the expansion of renewable energy and the $\mathrm{CO}_{2}$ price decline. In Sweden, the major factors have been renewable energy, the decline in final electricity demand, and larger volumes of water inflow into hydro reservoirs. The major factors that mitigated the price erosion were the nuclear phase-out in Germany and the increase in net exports, particularly in Sweden.

\section{METHODOLOGY}

This study is an ex-post evaluation of spot prices using a fundamental electricity market model. The properties of spot prices are discussed in the following subsection. Then, the model is introduced and, finally, some caveats of the factor decomposition are discussed (which apply to factor decompositions in general).

\subsection{Different Types of Power Prices: Spot vs. Financial Markets}

Electricity is traded on a range of wholesale markets that can be ordered along the time span between trading and delivery. On European financial markets, futures and forwards are traded between a few days and several years ahead. Futures and forwards are usually traded for delivery periods (contract durations) of between one day and one year. Spot markets can be split into two segments: day-ahead auctions, where electricity for next-day delivery is traded, and intraday markets, where trade takes place until gate closure at 15 to 60 minutes before delivery. Spot market contracts have a duration of between 15 minutes and one day. Real-time, or balancing, markets trade until seconds before real-time and products might be shorter than 15 minutes.

Spot market prices reflect market fundamentals. If market power is absent, settlement prices on spot markets reflect the marginal costs of electricity generation and the marginal willingness to pay for electricity consumption. For this study, it seems appropriate to abstract from market power and interpret prices as reflecting fundamentals: due to overcapacity, large interconnector capacity and little concentration among suppliers, market power abuse is not an issue on most European power markets, including Germany and Sweden (for Germany, see Bundeskartellamt 2011).

Financial markets, in contrast, reflect the expectations of market actors concerning future market fundamentals. A change in a future price implies that market actors have changed their view concerning some period in the future. Kallabis et al. (2016) study the plunge in electricity base futures with delivery in 2014 (the so-called "Cal14 base future") as traded between 2008 and 2013. Hence they investigate the market actors' changing expectations for 2014 as time unfolded. 
This paper studies spot prices between 2008 and 2015. More precisely, we investigate the yearly average of hourly contracts on day-ahead auctions. Differences between years should be attributed to changes in market fundamentals. Such changes in fundamentals might be or might not be anticipated, and hence can be accompanied by constant or changing prices of futures.

\subsection{The Fundamental Power Market Model EMMA}

The open-source Electricity Market Model EMMA is a techno-economic model of the integrated Northwestern European power system. It models both dispatch of and investment in power plants, minimizing total costs with respect to investment, production and trade decisions subject to a large set of technical constraints. For this study, no endogenous investment was modeled and installed generation capacity was taken from statistical sources. In economic terms, EMMA is a partial equilibrium model of the wholesale electricity market with a focus on the supply side. It was used to calculate the short-term optimum (equilibrium) and to estimate the corresponding hourly prices, generation, and cross-border trade for each market area. Technically, EMMA is a linear program with six million non-zero variables. EMMA has been used for eight peer-reviewed publications to address a range of research questions. ${ }^{1}$ It is also open-source: the model code as well as all input parameters and its documentation are freely available to the public under the Creative Commons BY-SA 3.0 license and can be downloaded from http://neon-energie.de/EMM.

Objective function and decision variables. For a given hourly electricity demand, EMMA minimizes total system cost, i.e. the sum of capital costs, fuel and $\mathrm{CO}_{2}$ costs, and other fixed and variable costs of generation, transmission, and storage assets. Investment and generation are jointly optimized for one representative year. Decision variables comprise the hourly production of each generation technology including storage, hourly electricity trade between regions, and annualized investment and disinvestment in each technology, including wind and solar power. The important constraints relate to energy balance, capacity limitations, and the provision of district heat and ancillary services. For this study, investment was disabled such that EMMA worked as a pure dispatch model.

Generation technologies. Generation is modeled as twelve discrete technologies with continuous capacity: (i) Two variable renewable energy sources with zero marginal costs-wind and solar power. Hourly wind and solar generation is limited by exogenous generation profiles, but can be curtailed at zero cost. (ii) Six thermal technologies with economic dispatch-nuclear power, two types of coal-fired power plants (lignite and hard coal), two types of natural gas-fired power plants (combined cycle gas turbines, CCGT, and open cycle gas turbines, OCGT), and lignite-fired carbon capture and storage plants (CCS). Dispatchable plants produce whenever the price is above their variable costs. (iii) A generic "load shedding" technology. Load is shed if prices reach its opportunity cost. (iv) Three hydro power technologies: run-off-the-river hydro power, hydro reservoir power, and pumped hydro storage; run-off-the-river hydro power is exogenous, while the other hydro technologies are optimized endogenously under turbine, pumping, inventory, inflow, and minimum generation constraints.

Spot price. The hourly zonal electricity price is the shadow price of demand, which can be interpreted as the prices of an energy-only market with scarcity pricing. In the electric engineering power system literature, the marginal costs of power generation are often labeled "system lambda", because they are derived from the shadow price of one of the constraints of an optimization model.

1. Hirth (2016), Hirth \& Steckel (2016), Hirth \& Müller (2016), Hirth (2015a), Hirth (2015b), Hirth \& Ueckerdt (2013), Hirth (2013). 
Demand elasticity. Demand is exogenous and assumed to be perfectly price inelastic at all prices but the very highest, when load is shed. Price-inelasticity is a standard assumption in dispatch models due to their short timescales.

Power system constraints. EMMA accounts for a large number of power system constraints. Two important classes of constraints concern combined heat and power generation and the provision of system services. Combined heat and power (CHP) generation is modeled as must-run generation. A certain share of the co-generating technologies lignite, hard coal, CCGT and OCGT are forced to run even if prices are below their variable costs. The remaining capacity of these technologies can be freely optimized. System service provision is modeled as a must-run constraint for dispatchable generators, which is a function of peak load and VRE capacity. Hirth (2015c) and Hirth \& Ziegenhagen (2015) provide background on the calibration procedure.

Trade. Cross-border trade is endogenous and limited by available transfer capacities. Endogenous investments in interconnector capacity have been disabled for this study. Within regions, transmission capacity is assumed to be non-binding.

Cycling costs. The model is linear and does not feature integer constraints. Thus, it is not a unit commitment model and cannot explicitly model start-up costs or minimum load. However, start-up costs are parameterized to achieve a realistic dispatch behavior. An electricity price is bid below the variable costs of assigned base load plants in order to avoid ramping and start-ups.

Deterministic. The model is fully deterministic. Long-term uncertainty surrounding fuel prices, investment costs, and demand development are not modeled. Short-term uncertainty concerning VRE generation (day-ahead forecast errors) is approximated by imposing a reserve requirement via the system service constraint, and by charging VRE generators balancing costs.

Geographical scope. EMMA is calibrated to Northwestern Europe and covers Germany, Belgium, Poland, The Netherlands, France, Sweden, and Norway. Due to space constraints, results are only presented here for Germany and Sweden, as they are representatives of quite distinct power systems: a system with mostly fossil power plants (Germany), and a nuclear-hydro dominated system (Sweden).

\subsection{Input Data}

Electricity demand, as well as electricity generation, of zero-variable-cost renewable energy (wind, solar, hydroelectricity) was taken from the International Energy Agency's Monthly electricity statistics. Data on net exports outside the mode region is from ENTSO-E Statistical factsheets. Table 1 summarizes these assumptions for different years, together with their sources.

German and Swedish 2015 prices are compared to their respective price peaks in 2008 and 2010. Figure 4 shows the volume shocks that hit the model region between 2010 and 2015 . Net electricity demand, defined as demand minus wind, solar and hydro generation as well as net exports, dropped by $11 \%$. The expansion of wind and solar energy, as well as the decline in final electricity demand, played a large role. Hydroelectricity generation had a small impact. Net exports increased, compensating for a quarter of the volume reduction. The change in net demand between 2008 and 2010 was positive, such that the difference between 2008 and 2015 is only about half of the difference of 2010-15.

Hard coal prices are the Northwest Europe Marker Prices provided by HIS McCloskey. Natural gas prices are German border import prices as reported by the International Monetary Fund (IMF). The carbon price is the price of EU ETS allowances (EUAs). Dollar-denominated prices were converted into Euro using exchange rate data from the European Central Bank. Figure 2 sum- 
Table 1: Important Volumetric Input Parameters and Data Sources

\begin{tabular}{lllll}
\hline Parameter & 2008 & 2010 & 2015 & Data source \\
\hline Electricity demand & $1705 \mathrm{TWh}$ & $1723 \mathrm{TWh}$ & $1647 \mathrm{TWh}$ & IEA Monthly electricity statistic \\
Wind + solar generation & $60 \mathrm{TWh}$ & $75 \mathrm{TWh}$ & $193 \mathrm{TWh}$ & IEA Monthly electricity statistic \\
Hydroelectricity output & $276 \mathrm{TWh}$ & $282 \mathrm{TWh}$ & $302 \mathrm{TWh}$ & IEA Monthly electricity statistic \\
Net exports of model region & $-38 \mathrm{TWh}$ & $38 \mathrm{TWh}$ & $90 \mathrm{TWh}$ & ENTSO-E Statistical factsheet \\
Net demand & $1331 \mathrm{TWh}$ & $1404 \mathrm{TWh}$ & $1246 \mathrm{TWh}$ & Own calculation \\
& & & $-6 \%$ vs. 2008 & \\
\hline
\end{tabular}

Numbers are shown for the entire model region (Sweden, Norway, Germany, France, Poland, Belgium, and The Netherlands). For 2015, electricity consumption and wind/solar generation were estimated based on data through November, because December data was not yet published.

Figure 4: The Change in Model-region Net Demand from 2010 to 2015

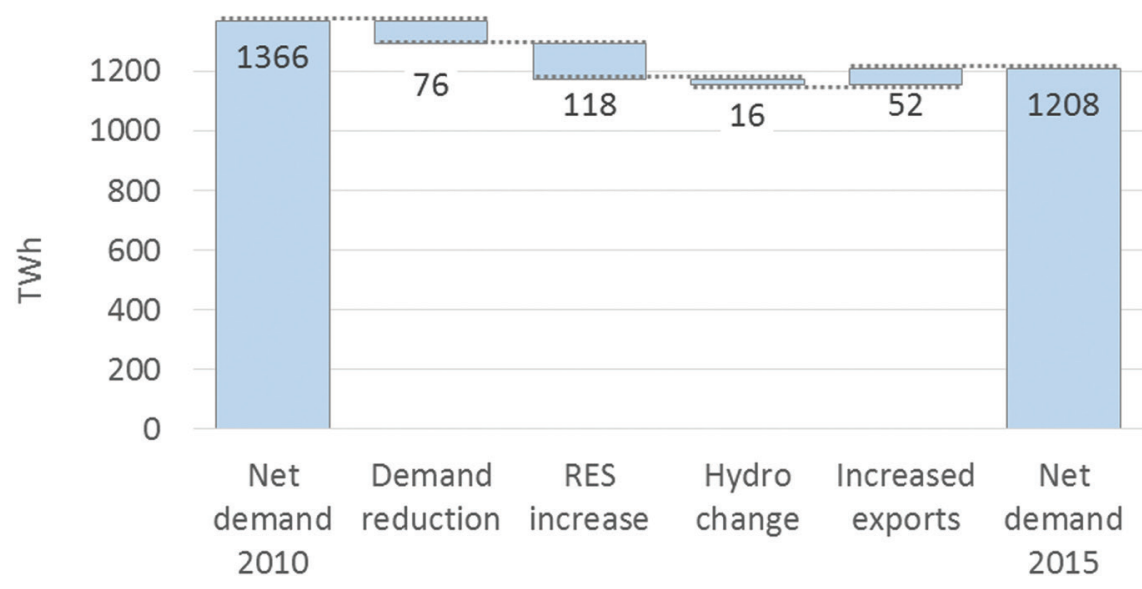

Net demand is demand to be served by thermal power plants.

marizes price assumptions for different years as well as their sources. While volume shocks on net demand are greater in the 2010-15 period than the 2008-15 period; the opposite is true for price shocks.

\subsection{Factor Decomposition: Some Remarks}

We would like to estimate the individual effect of each of the parameter changes on electricity prices, holding everything else fixed (ceteris paribus). This was done by first replicating electricity prices in a model of the power system for the base year (2008 or 2010) and the target year (2015). Taking the base year input dataset, one single parameter was substituted with its 2015 value, leaving all other parameters unchanged. The change in the modeled electricity price was interpreted as the price impact of these parameters.

This straightforward procedure is less innocent than it looks at a first glance. There are four caveats as follows. 
Table 2: Important price input parameters and data sources

\begin{tabular}{lllll}
\cline { 2 - 5 } Parameter & 2008 & 2010 & 2015 & Data source \\
\cline { 2 - 4 } Coal price & $150 \$ / \mathrm{t}$ & $92 \$ / \mathrm{t}$ & $59 \$ / \mathrm{t}$ & IHS McCloskey Northwest Europe Marker Price \\
& $12 € / \mathrm{MWh}$ & $8.4 € / \mathrm{MWh}$ & $6.4 € / \mathrm{MWh}$ & \\
Natural gas price & $30 € / \mathrm{MWh}$ & $21 € / \mathrm{MWh}$ & $22 € / \mathrm{MWh}$ & IMF German border import price \\
$\mathrm{CO}_{2}$ price & $25 € / \mathrm{MWh}$ & $16 € / \mathrm{t}$ & $6 € / \mathrm{t}$ & EUA price \\
\hline
\end{tabular}

All prices are nominal values (not inflation-adjusted). Dollar-denominated prices were converted into Euro using exchange rate data from the ECB.

Firstly, the sum of the individual effects does not necessarily equal the joint effect, which is the effect of changing all parameters at once. In a non-linear system such as power markets, this is generally the case. Consider the following drastic example to see economics behind this mathematical phenomenon: an increase in coal prices raises the electricity price, as does an increase in $\mathrm{CO}_{2}$ prices; however, an increase in both prices might not cause an increase in the electricity price, if all coal plants are driven out of the money, i.e. if they become extramarginal. We report the difference between the individual effects and the joint effect as "non-linear interaction effect".

Secondly, alternative base years, or benchmarks, exist. Particularly, the two following questions are not identical: "What would be the reduction of the electricity price if all parameters are set at 2010 levels, and only the RES supply is increased to 2015 levels?" (2010 benchmark) and "What would be the increase of the electricity price if all parameters are set at the 2015 level, and only the RES supply is decreased to 2010 levels?" (2015 benchmark). Any other year could be chosen as benchmark too. However, we chose the initial year as a benchmark.

Thirdly, individual effects are not identical to cumulative effects. We test factors individually, always starting with the full base year parameter set. In other words, we test each effect individually (separately), holding all other parameters at 2010 levels. A different approach would be to add changes on top of each other (cumulative). These approaches will usually yield different results. For example, the impact of a given change of renewable energy expansion is different at 2008 or 2015 coal prices. In a cumulative procedure, no interaction effect appears. Note that Figure 8 and Figure 9 could easily be mistaken for representing a cumulative procedure, which they do not.

Finally, if effects are added on top of each other (cumulative), the order matters. For example, if we started with an increase in renewable energy supply, and then decreased the demand, the result would be different to that obtained by decreasing the demand first, and then increasing the renewable energy supply. This is the reason why we do not follow such an approach.

\section{RESULTS}

First, historical prices were replicated. Then the parameters were individually substituted with those of 2015. To start with, we present German and then Swedish results.

\subsection{Replication of Historical Prices}

Figure 5 and Figure 6 compare historical prices to modeled shadow prices. Both observed and modeled prices are aggregated from hourly granularity to annual averages. Figure 7 contrasts the historical generation mix with the modeled mix. Both prices and quantities are replicated fairly well. Remaining differences are likely to stem from the inaccuracy of the model, such as the aggre- 
Figure 5: Yearly German Base Prices as Observed and Modeled

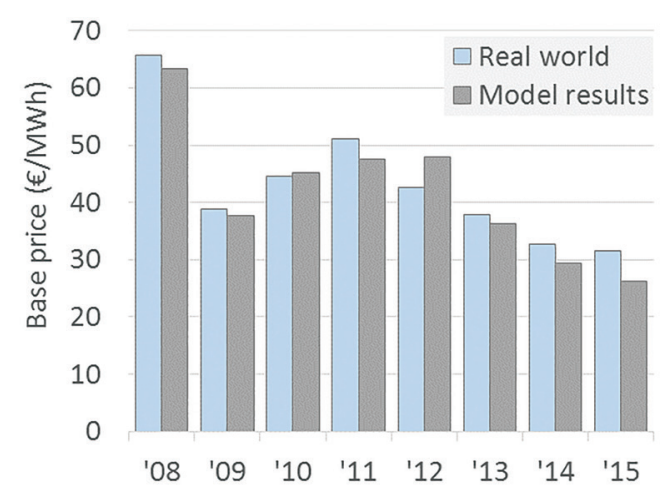

Figure 6: Yearly Swedish Base Prices as Observed and Modeled

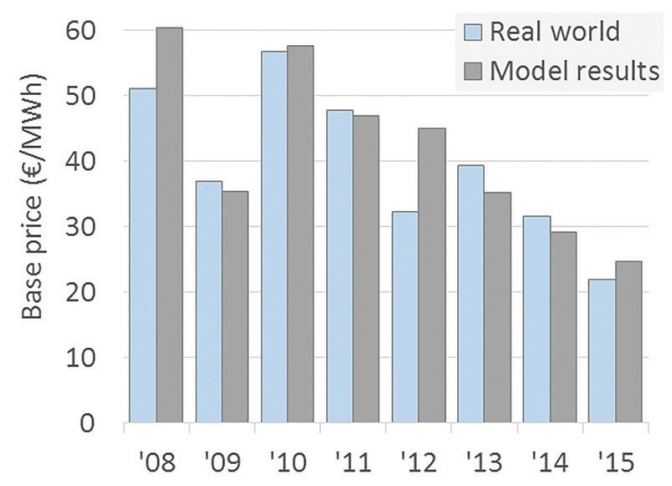

Figure 7: German Electricity generation Mix as Observed (left) and Modeled (right). Generation Patterns are Well Replicated

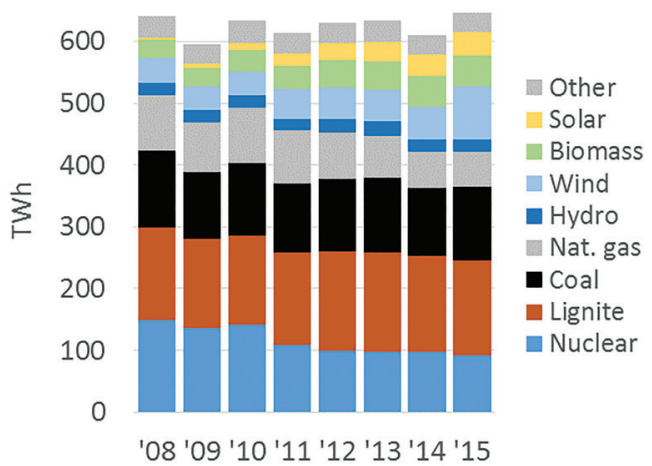

'08 '09 '10 '11 '12 '13 '14 '15

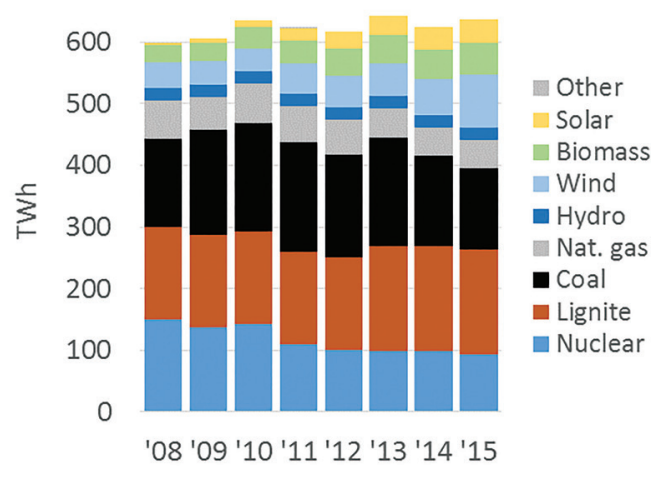

gation of power plants to technologies, which particularly effects coal. These model runs serve as the basis to changing individual factors in the following subsection.

\subsection{Germany: Impact Factors on Electricity Prices 2008-15}

German power prices peaked in 2008. Between that year and 2015, they declined by nearly two thirds. Figure 8 summarizes the modeled individual impact of all factors considered. The single largest contributing factor to the price erosion was the expansion of renewable energy (wind and solar power as well as bioenergy). In almost all European countries renewable energy has grown strongly during this time period; in Germany it nearly tripled. This rise has been caused by declining generation costs as well as implicit and explicit subsidies. According to our model runs, the expansion of renewable energy alone would have decreased German spot prices by $24 \%$. Note, however, that this is less than half the observed drop of $59 \%$. 
Figure 8: The Change of German Spot Prices from 2008 to 2015 Showing the Contribution of Ten Individual Factors

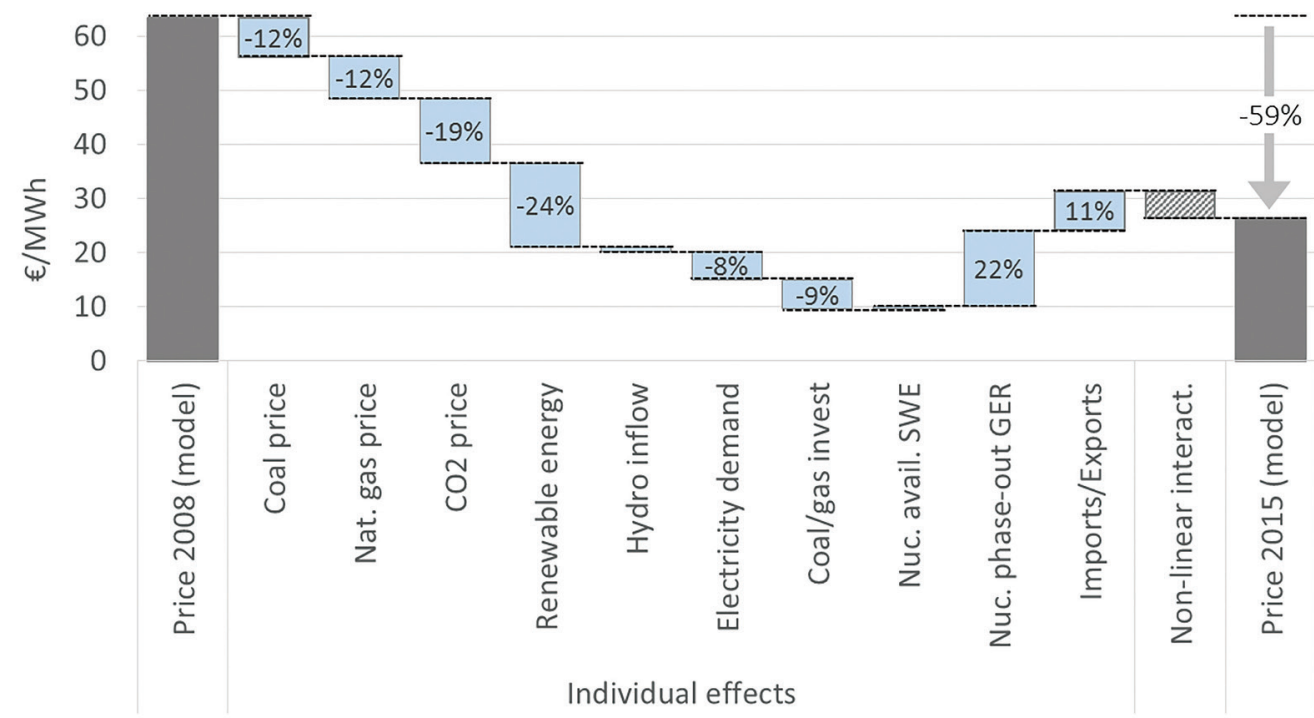

Numbers indicate the price impact of an individual factor relative to 2008 prices. For example, the effect of declining coal prices, holding everything else fixed, would have been a price decline of $12 \%$. Overall, prices declined by $59 \%$

The fall in fuel prices has also been important. Hard coal and natural gas prices contributed $12 \%$ each to the price drop. Even more important than this has been the collapse of the EU ETS price, adding another $19 \%$. The decline in electricity demand has had a moderate impact of $8 \%$ each. The investments in coal and natural gas-fired power plants reduced prices by $9 \%$. In other words, these model results suggest that overinvestment played a relatively small role. International trade, responding to the low prices in Germany, has compensated for the price drop. Ceteris paribus, the increase in net exports would have increased the power price by $11 \%$. The largest price-increasing element, however, was the German nuclear phase-out. After the Fukushima Daiichi nuclear disaster in 2011, the Japanese government decided to immediately shut down eight nuclear reactors. On its own, this intervention would have increased the power price by $22 \%$. Hence, if one defines the Energiewende as the combination of two policies, being the support of renewable energy and the phase-out of nuclear power, its net effect during the period under consideration has been negligible - a remarkable finding.

\subsection{Comparing the Results to Other Studies}

Three recent studies identify causal factors for the decline of German electricity wholesale prices: Kallabis et al. (2016), Everts et al. (2016), and Bublitz et al. (submitted). Qualitatively, the results of all four studies (including this) are similar. However, Kallabis et al. and Everts et al. find that the single largest contributing factor to the price drop was the $\mathrm{CO}_{2}$ price, Bublitz et al. find that the coal price contributed most, whereas this study identified renewable energy as the largest contributor. There are a number of reasons that help explain why results are not identical:

- Time horizon: This paper covers 2008-15, while Kallabis et al. cover 2007-14, Everts et al. 2008-14, and Bublitz et al. 2011-15. Important input parameters differ significantly between 
these time periods - recall Figure 1, Figure 2, and Table 1. During 2015 the $\mathrm{CO}_{2}$ price somewhat recovered, which helps explain why Kallabis et al. attribute a larger impact on carbon prices than this paper does.

- Geographic coverage: Kallabis et al. and Everts et al. model the German market, while Bublitz et al. and this study include a broader set of countries. The latter two studies consistently report that changed net export had a strong effect, something the former two studies miss out by design.

- Type of electricity price: Kallabis et al. model future prices while the three other papers model spot prices. As outlined in section 2.1, future prices reflect expectations while spot prices reflect fundamentals. If market fundamentals change but these changes are anticipated by market actors, spot prices will change but future prices will not.

- Other assumptions: the studies also differ in other crucial assumptions. Only Bublitz et al., for example, assume market power to be present.

Finally, in some cases, it is not results but their presentation that differs. For example, this study groups renewables together while others report solar and wind separately. Take Bublitz et al. as an example: if the estimated effects of solar and wind are added, the joint effect is larger than the impact of carbon prices, in line with this study. As the authors report the effects separately, however, no wonder they do not find renewable energy to be "the largest factor" while this study does.

\subsection{Sweden: Impact Factors on Electricity Prices 2010-15}

Sweden experienced a similar drop in spot prices since prices peaked, although the peak occurred in 2010. The same factors contributed to the drop, with the exception of natural gas prices that increased during this period and hence supported electricity prices (they declined 2008-15).

The quantitative role that individual factors have played, however, is quite different from the German case (Figure 9). The reason for the difference lies both in the different time frames under consideration, and the distinctions between the two power systems. Fuel and $\mathrm{CO}_{2}$ prices played a smaller role in the erosion of Swedish prices, both because there are fewer fossil fuel plants in the Nordic power system and because the decline in fuel prices over 2010-15 was lower than in the period 2008-15.

In contrast, three quantity shocks - the increase in renewable electricity generation, the additional hydroelectricity supply during the wet year of 2015, and the decline in final electricity demand - strongly depressed Swedish prices. The main reason for these volumetric shocks to have a greater effect in Sweden than in Germany lies in the nature of the Nordic power system; most electricity is supplied by power stations with zero or very low short-term marginal costs, such as nuclear power, hydroelectricity, and combined heat and power plants. Such a power system is always at the tip of a balance between demand and supply and is more sensitive to quantity shocks. This is reflected in significant year-to-year variations of the base price. Accordingly, the positive volume shock of increased net exports had an overwhelming role in stabilizing the price.

A note of caution: the non-linear interaction term in Sweden is much greater than in Germany. This is not surprising given the very large effects of individual factors. The large interaction effect makes the interpretation of individual contributions more difficult. For example, the role of increased net exports is likely to be smaller if previous price-reducing effects are taken into account (recall that each factor is modeled as a ceteris paribus assessment starting from the base year parameters). 
Figure 9: The Change of Swedish Spot Prices from 2010 to 2015 Showing the Contribution of Ten Individual Factors

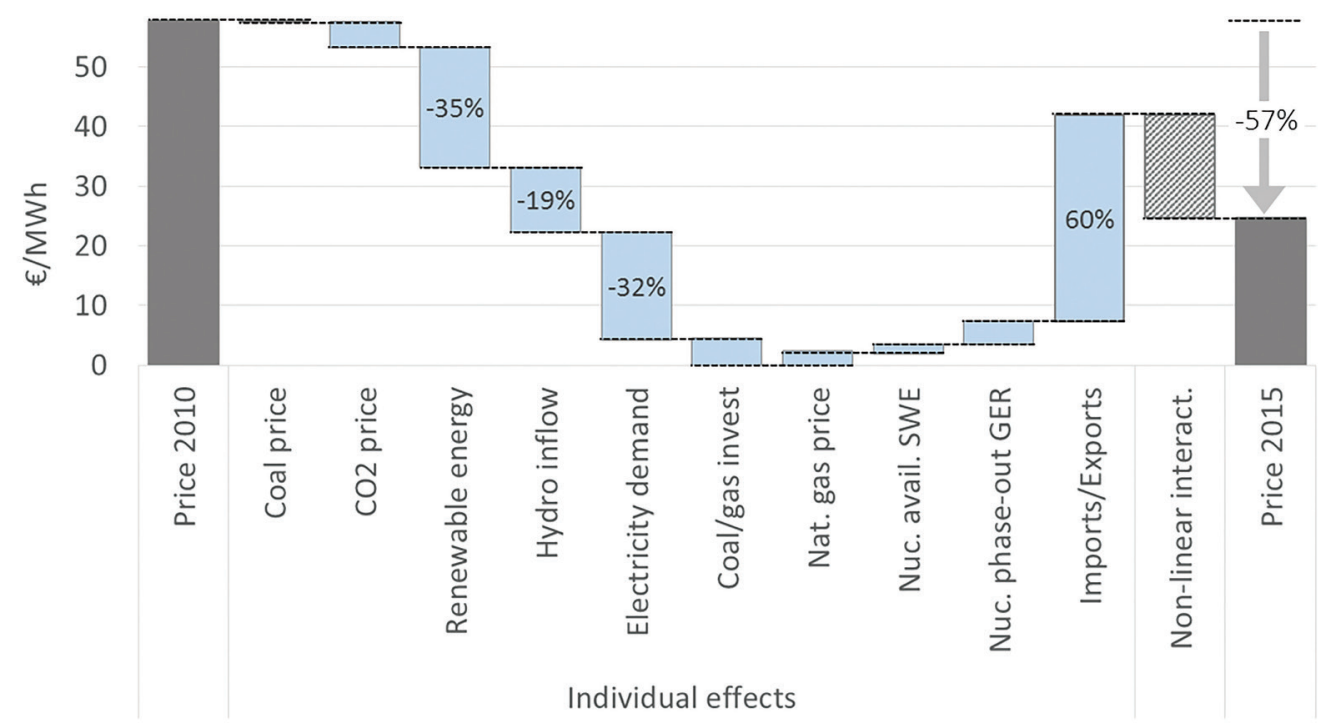

Numbers indicate the price impact of an individual factor relative to 2010 prices.

\subsection{Changing the Base Year: Looking Forwards or Looking Backwards?}

As explained above, the initial year (2008 or 2010) was used as reference or benchmark. Parameters from the final year (2015) were substituted one-by-one, leaving all other parameters at the initial levels. With the same right, one could use the final year as reference. Then the "impact of renewable energy" would be estimated by reducing renewable electricity supply to the levels of the initial year, leaving all other parameters at 2015 levels. This should yield different results, because the impact of additional electricity supply can have a different impact in an environment of high or low prices and high or low demand. These two alternative approaches are being compared here.

Surprisingly, in our case both procedures yield very similar results. In Germany, the increase of renewable energy production from 2008 to 2015 by itself would have depressed prices by EUR 15.5 per MWh (equal to the 24\% reported in section 3.2). Going back from 2015, reducing renewable energy production to 2008 levels, would have increased prices by EUR 13 per MWh (Figure 10).

In the case of Sweden, the effect is the same even down to the first digit (Figure 11). This indicates that our findings are remarkably robust with respect to the choice of the reference year, something that we had not expected.

\subsection{Isolating National Policies}

The largest single factor depressing wholesale prices, as identified above, is the expansion of renewable energy. This refers to expanding renewables across Europe. What was the effect of German renewable expansion on German prices? Figure 12 compares these two cases. The large impact of isolated German renewables - $90 \%$ of the impact of region-wide renewables growth - indi- 


\section{Figure 10: Germany: The Impact of Renewable Energy for Different Reference Years}

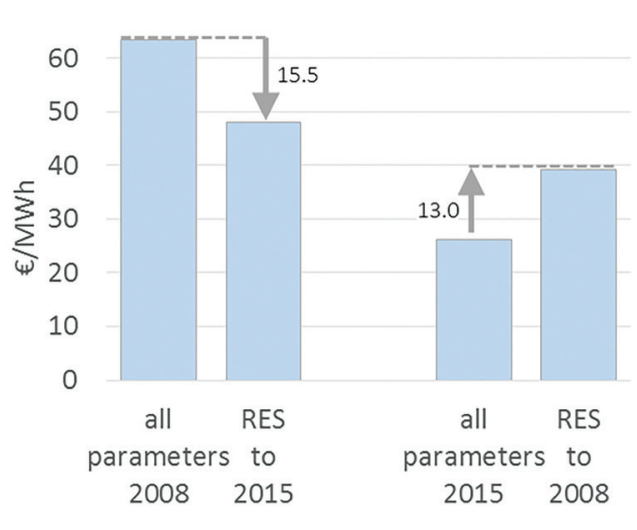

\section{Figure 11: Sweden: The Impact of Renewable Energy for Different Reference Years}

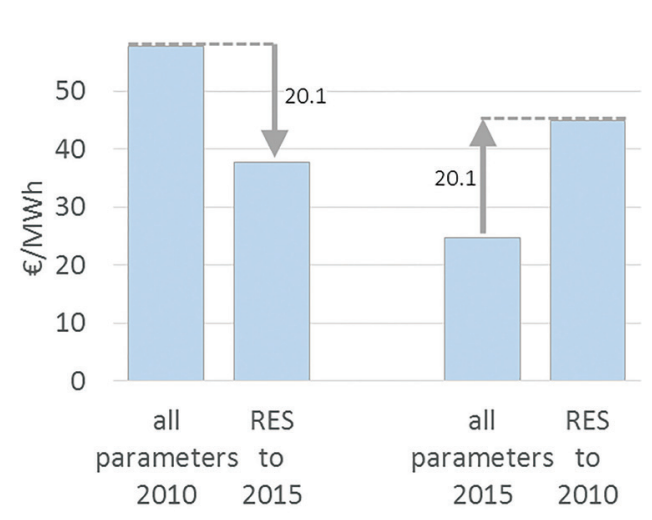

Figure 12: The Impact of European vs. German Renewable Expansion on the German Electricity Price

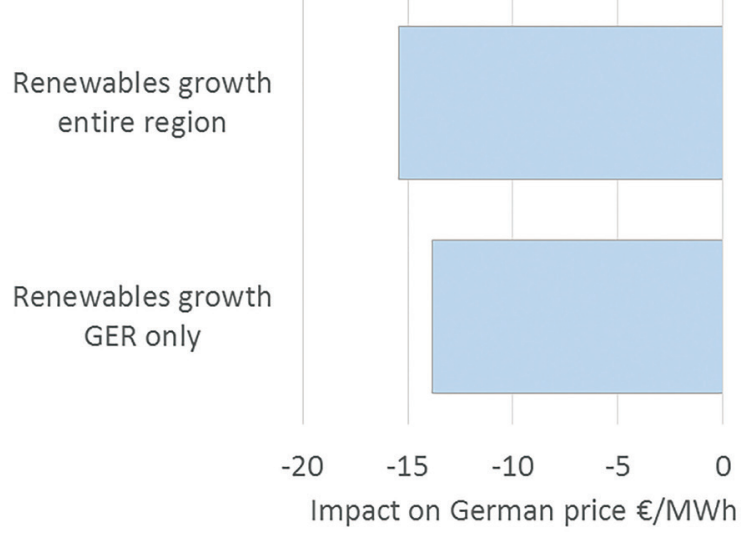

cates that there have been comparatively few cross-country spill-over effects. In other words: foreign renewables expansion had only a minor impact on German prices.

\subsection{Further Research}

The model used for this study is confined to the power sector of Northwestern Europe. It would be worthwhile to further explore the reasons for the price drop with a model that allows the sectoral and geographical scope to be increased. In particular, endogenizing the carbon market and fossil fuel markets would be a particularly promising line of further research. This would allow to account for a richer set of causal relationships and to identify more fundamental drivers, such as the macroeconomic recession that depressed the electricity price by decreasing electricity demand, but also via its downward effect on fuel and, particularly, $\mathrm{CO}_{2}$ prices. 


\section{CONCLUSIONS}

Understanding the past is interesting in itself, but it can also yield insights for the present. Several conclusions can be drawn from our findings. First, this study shows that the biggest decline of wholesale electricity prices in Europe in the liberalized era was the result of the coincidence of a number of price and volume shocks. However, it was not a "perfect storm"; the price decline was mitigated by several shocks, including policy interventions (the German nuclear phase-out) and market responses (trade flows responding to changes in relative prices). Second, the study also shows that two pillars of Germany's Energiewende, supporting renewable energy and phasing-out nuclear power, have balanced each other out in terms of impacts on the power price. Those who demand compensation for low prices "caused by politicians" (bearing in mind the market entrance of renewables) should be warned that a similar argument could be used to call for inverse compensation for the price-increasing effect of the nuclear shutdown. Finally, the study shows that electricity generation is a risky business. Prices are volatile and hard to predict. Moreover, future year-to-year volatility is likely to increase for two reasons: renewable energy is subject to substantial year-toyear output fluctuations and the price response of power systems with mostly low variable-cost generation tends to be more sensitive to volume shocks than fossil fuel-based systems, as our results for Sweden indicate.

\section{ACKNOWLEDGMENTS}

Funding by Svensk Energi is gratefully acknowledged. A previous version of this article was published as USAEE Working Paper 16-282. I would like to thank Mats Nilsson, Jonathan Mühlenpfordt, Marisa Bulkeley, Simone Dudziak, the participants of the European Energy Workshop as well as two anonymous reviewers for their valuable feedback. All remaining errors are mine.

\section{REFERENCES}

Bublitz, Andreas, Dogan Keles \& Wolf Fichtner (2016). "An analysis of the decline of electricity spot prices in Europe: Who is to blame?" Energy Policy (submitted).

Bundeskartellamt (2011). Sektoruntersuchung Stromerzeugung und-großhandel, Bonn.

Everts, Martin, Claus Huber \& Eike Blume-Werry (2016). "Politics vs markets: how German power prices hit the floor," The Journal of World Energy Law \& Business 9(2): 116-123. https://doi.org/10.1093/jwelb/jww005.

Gil, Hugo, Catalina Gomez-Quiles \& Jesus Riquelme (2012). "Large-scale wind power integration and wholesale electricity trading benefits: Estimation via an ex post approach.” Energy Policy 41: 849-859. https://doi.org/10.1016/j.enpol.2011.11.067.

Hirth, Lion \& Falko Ueckerdt (2013). "Redistribution Effects of Energy and Climate Policy: The Electricity Market.” Energy Policy 62: 934-947. https://doi.org/10.1016/j.enpol.2013.07.055.

Hirth, Lion \& Inka Ziegenhagen (2015). "Balancing power and variable renewables: Three links." Renewable \& Sustainable Energy Reviews 50: 1035-1051. https://doi.org/10.1016/j.rser.2015.04.180.

Hirth, Lion \& Jan Steckel (2016). "The role of capital costs for decarbonizing the power sector." Environmental Research Letters (submitted). https://doi.org/10.1088/1748-9326/11/11/114010.

Hirth, Lion \& Simon Müller (2016). “System-friendly Wind Power.” Energy Economics 56: 51-63. https://doi.org/10.1016/j. eneco.2016.02.016.

Hirth, Lion (2013). "The Market Value of Variable Renewables: The effect of solar wind power variability on their relative price.” Energy Economics 38: 218-236. https://doi.org/10.1016/j.eneco.2013.02.004.

Hirth, Lion (2015a). "The Optimal Share of Variable Renewables: How the Variability of Wind and Solar Power affects their Welfare-optimal Deployment.” The Energy Journal 36(1): 127-162. https://doi.org/10.5547/01956574.36.1.6.

Hirth, Lion (2015b). “The Market Value of Solar Power: Is Photovoltaics Cost-Competitive?” IET Renewable Power Generation 9(1): 37-45. https://doi.org/10.1049/iet-rpg.2014.0101.

Open Access Article. 
Hirth, Lion (2015c). "Minimal Thermal Generation in Power Systems-Inferring Private Cost Parameters from Observed Firm Behavior." USAEE Working Paper 15-203.

Hirth, Lion (2016). "The benefits of flexibility: The value of wind energy with hydropower." Applied Energy 181, $2010-223$. https://doi.org/10.1016/j.apenergy.2016.07.039.

Kallabis, Thomas, Christian Pape, and Christoph Weber (2016). "The plunge in German electricity futures prices-Analysis using a parsimonious fundamental model”, Energy Policy 95: 280-290. https://doi.org/10.1016/j.enpol.2016.04.025.

MacCormack, John, Adrian Hollis, Hamidreza Zareipour \& William Rosehart (2010). "The large-scale integration of wind generation: Impacts on price, reliability and dispatchable conventional suppliers." Energy Policy 38(7): 3837-3846. https:// doi.org/10.1016/j.enpol.2010.03.004.

Mount, Timothy D., Surin Maneevitjit, Alberto J. Lamadrid, Ray D. Zimmerman \& Robert J. Thomas (2010). "The Hidden System Costs of Wind Generation in a Deregulated Electricity Market.” The Energy Journal 33(1): 173-198. https://doi. org/10.5547/ISSN0195-6574-EJ-Vol33-No1-6.

Munksgaard J. \& PE Morthorst (2008). "Wind power in the Danish liberalized power market—policy measures, price impact and investor incentives.” Energy Policy 36(10): 3940-3947. https://doi.org/10.1016/j.enpol.2008.07.024.

O’Mahoney, Amy \& Eleanor Denny (2011). "The Merit-Order Effect of Wind Generation in the Irish Electricity Market." Proceedings of the 30th USAEE conference, Washington.

Olsina, Fernando, Mark Röscherb, Carlos Larissona \& Francisco Garce (2007). "Short-term optimal wind power generation capacity in liberalized electricity markets.” Energy Policy 35: 1257-1273. https://doi.org/10.1016/j.enpol.2006.03.018.

Rathmann, M. (2007). “Do support systems for RES-E reduce EU-ETS-driven electricity prices?” Energy Policy 35(1): 342-349. https://doi.org/10.1016/j.enpol.2005.11.029.

Sáenz de Miera, G., P. del Río González, \& I. Vizcaíno (2008). “Analysing the impact of renewable electricity support schemes on power prices: The case of wind electricity in Spain." Energy Policy 36: 3345-3359. https://doi.org/10.1016/j. enpol.2008.04.022.

Sijm, Jos, Karsten Neuhoff \& Yihsu Chen (2006). " $\mathrm{CO}_{2}$ cost pass-through and windfall profits in the power sector." Climate Policy 6: 49-72. https://doi.org/10.1080/14693062.2006.9685588. 


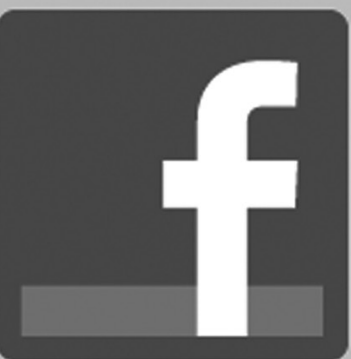

Connect with IAEE

on facebook

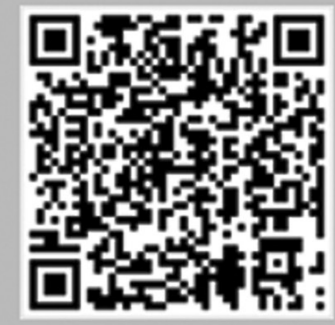

